\title{
Healthcare scenario in rural western India: A cross sectional survey
}

\author{
Suchitra Mankar ${ }^{\mathrm{a}}$, Harikrishnan Vannadil ${ }^{\mathrm{b}, *}$, Sunandan Bhatta ${ }^{\mathrm{b}}$, Singh Archana ${ }^{\mathrm{b}}$ \\ a Managing Director at Doorstep Health Services Pvt Ltd., Pune, 411027, India \\ ${ }^{\mathrm{b}}$ Resident (Ophthalmology), AFMC, Pune, 411040, India
}

\section{Introduction}

Access to healthcare is a basic requirement of any community. ${ }^{1-3}$ Their availability and optimum utilisation is ensured by the administration by ensuring quality standards acceptable to the local populace. ${ }^{3}$ The health services thus provided should be independent of the economic and social background of the care seeker. However, the truth is far from the ideal situation. ${ }^{4,5}$

India is a country with mixed demographics. ${ }^{6}$ There is a considerable difference in the quality of services provided in the urban and rural setting. ${ }^{4}$ The urban setting is dominated by the presence of private or corporate medical giants providing premium services catering to the economically sound with some form of public facility addressing the needs of the under privileged. In contrast, informal medical practitioners dominate the healthcare in rural India. These informal medical practitioners range from uneducated quacks to professionally trained private practitioners. The administration has numerous intermediaries who are entrusted the responsibility to bridge this gap in healthcare services like ASHA \& ANM. The performance of these intermediary services is essential for the penetration of healthcare at the grass root level. In the past few decades, the government is struggling to improve healthcare access to its citizens. In spite of these efforts, the outcome remains far from satisfactory. The variety of reasons range from inefficient implementation to non-acceptance from the local community. In such situation, presence of private players with out-of-pocket payment mechanism compounds the difficulty in presence of variable socioeconomic background. ${ }^{4,7}$

In order to gain an insight into the healthcare delivery mechanism of the rural population of this country, a health care accessibility survey was conducted in 3 selected villages of Maharashtra state in India. We evaluated the demographic and economic parameters influencing healthcare delivery along with the state of delivery modalities. The interest in this selected population is due to the rural background and perceived paucity of adequate medical facilities. The results and further analysis of which is presented in this paper.

\subsection{Aims \& objectives}

The aim of the study is to develop a comprehensive data on the healthcare services status in a rural Indian community. The objectives defined were as follows. Firstly, ascertain the availability of public and private healthcare machinery in the selected rural population. Secondly, study the financial impact of healthcare delivery system on the user.

\section{Materials and methods}

The methodology adopted was a Cross- Sectional point prevalence study using stratified random sampling based on the household as a unit. A $20 \%$ sample of the population was decided upon keeping logistics and time frames in mind.

Instruments used were -

a) Household Survey Questionnaire. This gathered information from households like Demography, Education, Income, Priorities of villagers and Socioeconomic Indicators.

b) Unstructured Interviews with eight village residents. The questionnaire was validated in a previous survey undertaken for an NGO whose data is not available for publication.

c) Village Inspection to see state of the village in terms of medical facilities. 2017.

The survey was conducted in three stages during the years 2016 \&

a) Stage I

a Preparation and development of study Framework

b Review of Policies, identify secondary data

c Creation of tools and road map

b) Stage II

a Field research and data collection

b Primary data: questionnaire; house visits; interviews

c Secondary data: Census Data; Panchayat and PHC data; District Health Officer; Literature

c) Stage III

a Documentation and Analysis of data

b Draft Report/Presentation

c Final Report

\footnotetext{
${ }^{*}$ Corresponding author. Dept of Ophthalmology, AFMC, Pune, 411040, India.

E-mail addresses: suchitramankar@gmail.com (S. Mankar), hvannadil@gmail.com (H. Vannadil), sunandanbhatta@gmail.com (S. Bhatta).
} 


\section{Results}

\subsection{General information}

The three villages -Village A, Village B and Village C selected for the survey by the study group near XYZ. XYZ is a Taluka (administrative district for taxation purposes, typically comprising a number of villages) in the district of Satara in Maharashtra, India. The town is about $59 \mathrm{~km}$ north-east of the city of Satara and about $110 \mathrm{~km}$ from Pune. The climate is an inland climate of Maharashtra. Summer in XYZ is comparatively hot, and dry, compared to neighbouring inland cities. Maximum temperatures exceed $40^{\circ} \mathrm{C}\left(104^{\circ} \mathrm{F}\right)$ every summer and typically range between 38 and $45^{\circ} \mathrm{C}\left(100-113^{\circ} \mathrm{F}\right)$. The area does not receive much rainfall from and has been declared as a drought-prone place by the Government. Winters are short and mild and the climate is pleasant during this period from December to February.

\subsubsection{The Three Villages}

Though the three villages were quite similar in some ways they were unique in many other. Village A was the largest. Village B the smallest and Village $C$ was in between. The gram Panchayat representatives of Village $C$ and Village $B$ were enthusiastic, keen and provided a lot of support during the survey in terms of energy and time. Village A though the largest seemed to be politically divided and also involved in society elections during the period of survey. Village A Gram Panchayat was not really involved and data collection was a challenge. The offshoots of these village called Vastis-were a study in themselves. Many had large bungalows and the residents appeared distinctly well to do. On the other hand some areas near Village $\mathrm{C}$ appeared distinctly poor with kuccha (mud bricked) house and an air of neglect all around.

\subsubsection{Demography}

Population in the villages as provided by the Panchayat Samiti is given in Table-1.

It was seen that census population did not all reside in the villages. This applied especially to males and married women who had often moved to Pune/Mumbai for jobs. It was learnt that people were selling land as farming was unviable, land costs had appreciated and the educated youth were not keen on farming their land.

The number of births and deaths in the villages in 2014-2015 (Panchayat Samiti - village administration) is as given in Table-2 below. This works out to an average Crude death rate of 3.7 and birth rate of 11.1 per 1000 population for the year 2014-2015. This is much lower than that reported for Maharashtra state -Death rate of 6.2/1000 and birth rate of $16.4 / 1000$.

\subsubsection{Religion}

$96.9 \%$ of this population was Hindu, with the remainder comprising Muslims and Buddha. The latter belonged to Village A.

\subsubsection{Caste}

Marathas were the predominant category. Village A had the largest number of persons from SC, ST, OBC and other caste.

\subsubsection{Languages}

$12.2 \%$ could only speak and understand Marathi, while $82.6 \%$ could speak, understand read and write it. $54.6 \%$ and $11.8 \%$ could speak,

Table 1

Population of villages.

\begin{tabular}{llll}
\hline Village & Households & Total Population & Male \\
\hline Takobaichiwadi & 128 & 599 & 304 \\
Saswad & 729 & 3523 & 1762 \\
Mulikwadi & 262 & 1262 & 648 \\
\hline
\end{tabular}

Table 2

Births and deaths in past two years.

\begin{tabular}{|c|c|c|c|c|c|c|}
\hline \multirow[t]{2}{*}{ Village Name } & \multirow[t]{2}{*}{ Year } & \multirow[t]{2}{*}{ Births } & \multicolumn{4}{|l|}{ Deaths } \\
\hline & & & $0-1 \mathrm{yrs}$ & $1-5$ yrs & Adults & Total \\
\hline \multirow[t]{2}{*}{ Saswad } & 2013-14 & 59 & 0 & 0 & 22 & 22 \\
\hline & 2014-15 & 38 & 0 & 1 & 12 & 13 \\
\hline \multirow[t]{2}{*}{ Takobaichiwadi } & 2013-14 & 4 & 0 & 0 & 4 & 4 \\
\hline & 2014-15 & 12 & 0 & 0 & 2 & 2 \\
\hline \multirow[t]{2}{*}{ Mulikwadi } & 2013-14 & 17 & 1 & 0 & 6 & 7 \\
\hline & 2014-15 & 10 & 1 & 0 & 3 & 4 \\
\hline
\end{tabular}

understand read and write Hindi and English respectively. There was one person who was quite accomplished in Spanish.

\subsubsection{Family Type and size}

$62.1 \%$ of families were nuclear, $29.8 \%$ joint families and $8 \%$ being three-generation families. This indicates a change in family structures. The average family size was 4.5 .

\subsubsection{Education}

The education level of persons above 21 years of age is as given in Fig-1 below. The population had a literacy rate of $81.65 \%$. That of Maharashtra was a little better at $82.34 \%$ (Census, 2011). ${ }^{6}$ Nearly half the population was educated to primary school or less. The good news is that most children up to 15 years of age were attending school. The Net Enrolment Rate of Maharashtra is $86.42 \%$ for 6-10 year olds. In this study it was $80 \%$, and increased to $85.71 \%$ in the age group $11-15$ years. Then it dropped. The dropout rate however continued to increase with age, more girls dropping out than boys. It was seen that in the age group 21-25 years more girls were studying as compared to boys. See Table-3.

\subsubsection{Total Monthly Family Income}

There were a total of $8.7 \%$ households with an income less than Rs $2500 /-$ pm. About $75 \%$ of the population earned less than Rs 17,500/$\mathrm{pm}$. There was a couple of families in Village A and Village $C$ with an income of more than a lakh a month. This meant that most families had an income of about Rs 90 per person per day. See Fig-2.

\subsubsection{Food spend}

Most spent Rs 2000 or less on food per month. Those with low incomes spent as less as Rs 500/- per month on food. Food expenditure was significantly related to family income. It was noticed that even if they owned, cows, or hens, the family would keep very little for selfconsumption and would sell the produce, as money was more attractive to them. See Fig-3.

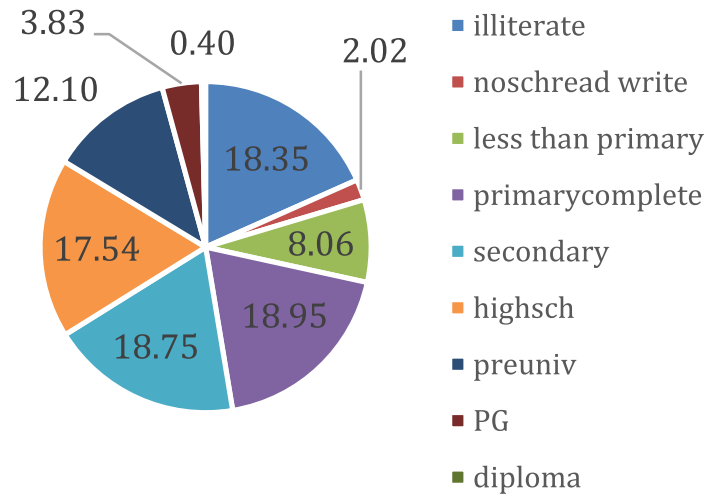

Fig. 1. Education in persons 21 years and above. 
Table 3

Percentage of boys and girls attending school by age group.

\begin{tabular}{llllll}
\hline Age Group & $\begin{array}{l}\text { Total } \\
\text { Males }\end{array}$ & $\begin{array}{l}\text { Male attending } \\
\%\end{array}$ & $\begin{array}{l}\text { Total } \\
\text { Females }\end{array}$ & $\begin{array}{l}\text { Female } \\
\text { attending\% }\end{array}$ & Total \\
\hline Age-1-5 & 15 & 66.67 & 12 & 33.33 & 51.85 \\
06 to 10 & 19 & 73.68 & 16 & 87.50 & 80.00 \\
11 to 15 & 23 & 100.00 & 19 & 68.42 & 85.71 \\
16 to 20 & 31 & 80.65 & 28 & 71.43 & 76.27 \\
21 to 25 & 47 & 12.77 & 41 & 19.51 & 15.91 \\
26 to 30 & 45 & 0.00 & 27 & 0.00 & 0.00 \\
& 180 & & 143 & & \\
\hline
\end{tabular}

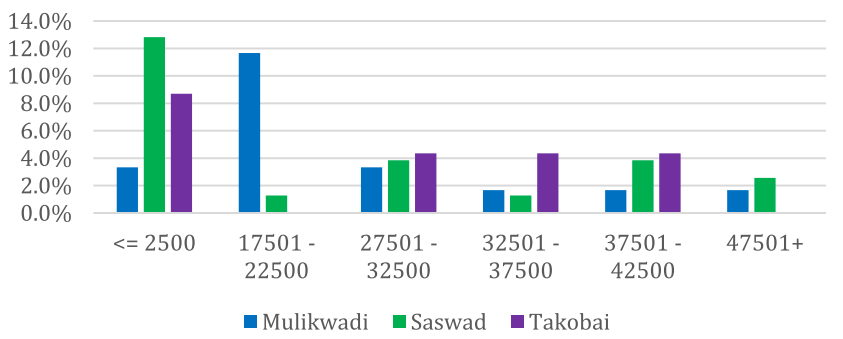

Fig. 2. Total monthly family incomes.

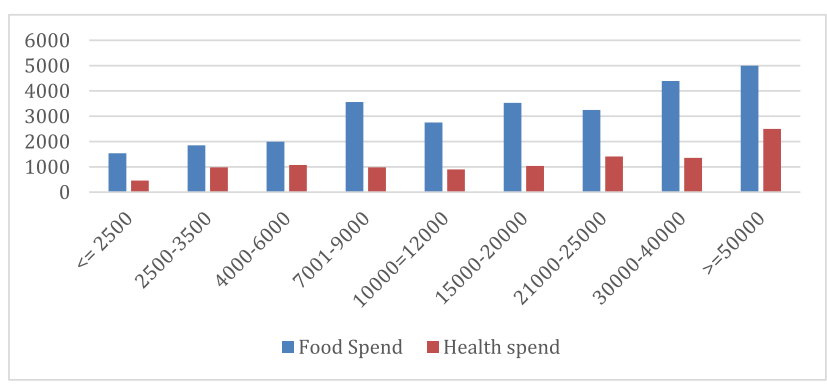

Fig. 3. Monthly expenses on food and health.

\subsubsection{Health Spend}

Most families spent about Rs 850/- per month on their health needs. This increased with increasing income. The cost of care included a bus journey (Rs 70/-); Doctor Fee (Rs 50-Rs 100/-) and medicines (Rs 100-200/-). The villager also lost in terms of his daily wages that day.

\subsubsection{ASHA and AWW}

We interacted with many of the ASHA (Accredited Social Health Activist) and AWWs (Anganwadi Workers). The ASHAs did know people of the village and could provide us data on births, deaths, pregnancies and malnourishment. They were well versed with Immunization and Vit A activities. However their registers and written records were in old tattered notebooks maintained haphazardly. All were demotivated on account of the poor remuneration they received. One had left her job as she said it took too much time. It seemed that there was a lack of supervision, nurturing, motivation and training for these workers. These workers operated only in maternal and child health related activities. As an example, they knew how many women were pregnant and would monitor their Blood Pressure, but could not say how many villagers were hypertensive and had never measured their Blood pressure. ASHAs can now call 104 a toll free medical helpline from their mobiles for help. This seemed to be useful to solve day-to-day problems.

\subsubsection{Immunization}

We saw a good immunization OPD (Out Patient Department) being run at the SC (Sub Centre) for primary Immunization. It was well attended, the mothers were knowledgeable and the atmosphere was positive. The immunization-completed rate for children up to completed years was for this population was $96.4 \%$, which compares well with state figures.

\subsubsection{Anganwadis}

All the Anganwadis were visited. Everywhere, the numbers enrolled were much higher than the numbers present. We observed distribution of Vit A, and deworming of children. The AWW were scared of giving tablets to small children. They expressed a need to have a doctor to provide advice as and when required. Weight record of children was maintained. However the children appeared unclean, unkempt and even malnourished. VCDC (Village Child Development Centre) based diet or Rs 1200/- per month was provided to the undernourished. We learnt that often the food at Anganwadis also was given to the children to take home. If this happened all siblings would share it.

\subsubsection{Local doctors}

As the trip to PHC (Primary Health Centre) takes time, money and since the timings do not suit the villagers, they use local visiting doctors. They are all either BAMS (Ayurvedic doctor) or BHMS (Homeopathic doctor) practising an unorthodox form of allopathic medicine. Antibiotics and palliative medication with a liberal use of painkillers, injection and saline drips is practiced. The doctors are available usually for $2 \mathrm{~h}$ a day. Interview with a doctor at Village $\mathrm{C}$ revealed that joint pains and body ache were the commonest complaint. There would occasionally be a spate of diarrhoea cases or upper respiratory infections. He stated that there were a fair number of cases of diabetes and hypertension but compliance with medical regimes were very poor; probably because villagers could not afford the expense of regular trips to the doctor and the cost of chronic medication. There was no Laboratory available nearby. Any investigation including X-Ray or Ultrasound could only be done at Village D (A village outside survey area). The nearest private practitioner was located at a distance approximately $30 \mathrm{~km}$.

\subsubsection{Ambulance}

This service though started by the State Government (call 108/102) did not always keep good time. One could never be sure as to when it would arrive. The ASHA from Village B brought out that she would never take on responsibility for taking delivery cases to government $\mathrm{PHC} /$ Hospital, because the pregnant lady would ask for free ambulance service, which would never come on time and the ANM (Auxiillary Nurse Midwife) was afraid that the delivery, if it occurred as a result of the delay at home/in the ambulance, would be her burden. Thus most of the women had their delivery in private hospitals. Four private hospitals operated at Lonand or else local transport was used.

A Bachelors of Commerce Graduate ran the Pharmacy at Village A. Registration was in the name of his wife who had a diploma in Pharmacy, but who rarely visited the shop. He too stated that new generation antibiotics, antacids, and medicine for body ache are what were sold the most. Many persons also purchased medicines directly from him.

\subsubsection{Health Insurance}

Only $12.56 \%$ households claimed to have health insurance. Half of these had private insurance and the remaining had either employee insurance or was part of a health scheme.

\subsubsection{Health related Training}

Hardly anyone in the villages had any health related training not even in first aid. This applied to schoolteachers, gram panchayat members, ASHAs, AWWs, youth etc. Considering the poor health facilities and the distance from hospitals, health training would be a boon to this community.

\subsubsection{Medical Care Access and Preference}

Half the respondents used whatever medical facility was available in 


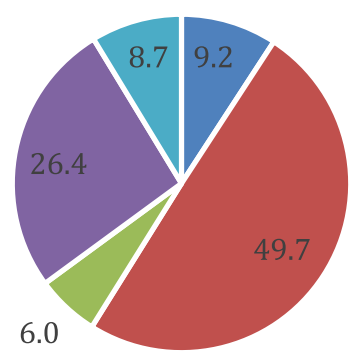

- Govt facility-village

- Pvt facility village

- Gov facility outside village

- Pvt facility outside village

- cant say

Fig. 4. Accesses to medical services.

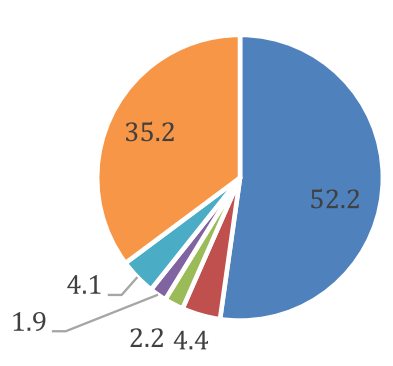

" no nearby facility
- timings not
convenient
" health persons absent
- long waiting
- Poor quality

Fig. 5. Reasons for not using government medical facility.

the village, and a quarter used a private facility outside the village. $9.2 \%$ of the total population used the government facility in the villagethe SC at Village A (all these respondents belonged to Village A). Only $6 \%$ used the government facility outside the village. This very significant difference needs to be noted to plan medical programs. Please see Fig-4.

\subsubsection{Reasons for not using Government Facility}

$52.2 \%$ used the village private facility, as there was no doctor available nearby. Inconvenient timings, distance, and lack of care were the other reasons. $35.2 \%$ did not give a clear-cut reason. See Fig-5.

\subsubsection{Priority in Expenditure}

On an average, after food, healthcare was the highest followed closely by electricity and then education, transport and fuel. This prioritization tells us the needs of the people. It is of concern that food, healthcare, electricity - very basic requirements are not available to most. See Table-4 and (see Fig. 6) Fig-7.

\subsubsection{Priority in Health Expenditure}

On average Doctor, Medicines, Ambulance and emergency services were the highest priority to villagers-their highest needs. See Table- 5 and Fig-8.
Table 4

Priority in expenditure.

\begin{tabular}{llllllll}
\hline & I & II & III & IV & V & Average & Priority \\
\hline Food & 81 & 35 & 18 & 11 & 5 & 30 & I \\
Healthcare & 25 & 46 & 31 & 19 & 10 & 26.2 & II \\
Electricity & 2 & 10 & 31 & 39 & 44 & 25.2 & III \\
Education & 32 & 25 & 22 & 7 & 10 & 19 & IV \\
Transport & 6 & 15 & 17 & 25 & 30 & 18.6 & V \\
Fuel & 0 & 8 & 20 & 26 & 22 & 15.2 & VI \\
Shelter & 2 & 10 & 10 & 18 & 10 & 10 & \\
Cant say & 6 & 11 & 12 & 13 & 17 & 11.8 & \\
Other & 7 & 1 & 0 & 3 & 13 & 4.8 & \\
Total & 161 & 161 & 161 & 161 & 161 & & \\
\hline & & & & & & &
\end{tabular}

\subsubsection{Cost of Medicines}

$50.2 \%$ - believed that cost of medicines was very high as compared to other health care costs. $28.6 \%$ disagreed and a large percentage$21.1 \%$ could not say. The unfair part was that in spite of spending money people were not getting appropriate and authentic medicine at the right price.

\section{Discussion}

The survey conducted at three villages in India reveals the paucity of adequate healthcare services in this region. These villages are located between 60 and $100 \mathrm{~km}$ from the nearest urban region. The distance plays a crucial part in the availability of health provisions as reflected in previous studies as well. ${ }^{7,8}$ The study population resides in a warm and dry climate and requires more attention to health needs in terms of basic amneties during the harsh weather. The absence of adequate rains with dry spells in some years have a deliterious effect on the overall health of the population prompting better performance of primary care facilities. $^{9,10}$

There exist large quantum of people who have migrated to urban areas for better quality of life as evident from the disparity of census population and the survey findings. Such outward migration has been demonstrated in various other studies where the educated and skilled population is lost to urban areas. ${ }^{11,12}$ This pattern leads to loss of agricultural potential of the region resulting from non-availability of young workforce.

During the survey, it was found that $8.7 \%$ of the population was below the poverty line and there were a total of $8.7 \%$ households with an income less than Rs 2500/- pm (USD 40). This places a large number of households under the limit of extreme poverty transcending the international poverty line. ${ }^{13}$ However, there exist a huge disparity in the minimum and maximum-earning households. In spite of the low income, majority of the families spend a considerable portion on dietary expenses. The food expenditure was found to be as less than $25 \%$ of the total income in few households. In the scenario of low income with major expenditure on food, healthcare expense takes second priority. A 2007 study in Bengal reported annual per household expenditure on

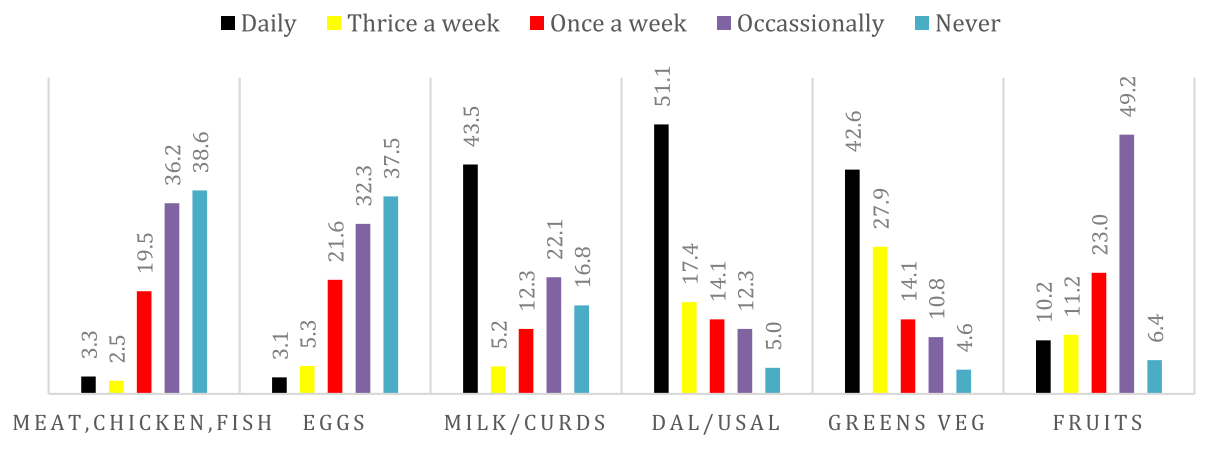

Fig. 6. Dietary habits by frequency (percent). 


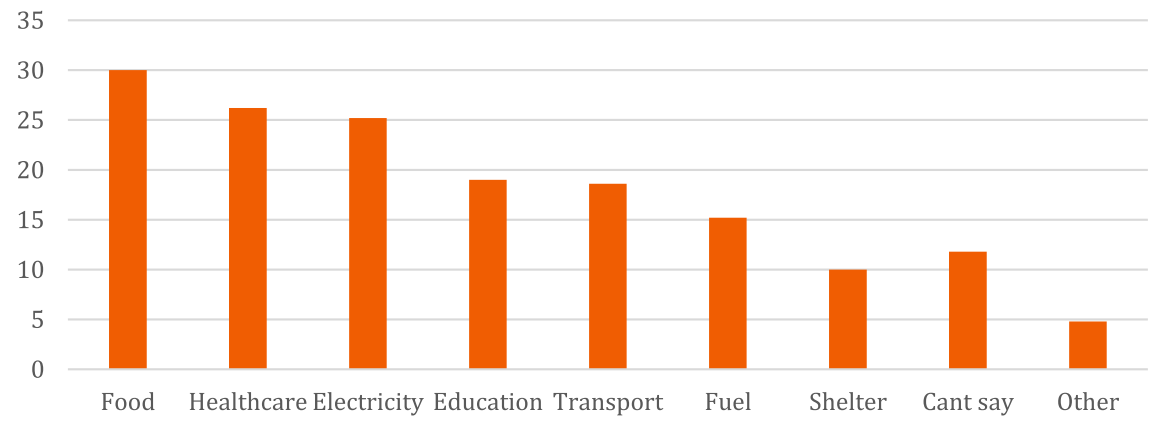

Fig. 7. Priority IN expenditure.

Table 5

Priority in health expenditure.

\begin{tabular}{llllllll}
\hline & I & II & III & IV & V & Average & Priority \\
\hline Doctor & 91.0 & 36.0 & 14.0 & 6.0 & 3.0 & 30.0 & I \\
Medicine & 18.0 & 83.0 & 24.0 & 14.0 & 5.0 & 28.8 & II \\
Ambulance & 5.0 & 14.0 & 56.0 & 41.0 & 8.0 & 24.8 & III \\
Emergency Services & 13.0 & 3.0 & 34.0 & 34.0 & 18.0 & 20.4 & IV \\
School Health & 20.0 & 5.0 & 3.0 & 27.0 & 34.0 & 17.8 & V \\
Health Trg & 6.0 & 9.0 & 17.0 & 14.0 & 41.0 & 17.4 & VI \\
Laboratory & 1.0 & 0.0 & 2.0 & 8.0 & 15.0 & 5.2 & VII \\
Cant say & 7.0 & 11.0 & 11.0 & 17.0 & 37.0 & 16.6 & \\
& 161.0 & 161.0 & 161.0 & 161.0 & 161.0 & & \\
\hline & & & & & & &
\end{tabular}

OPD visits, chronic diseases, and hospitalizations as INR 1170, INR 2637 and INR 4340 respectively. ${ }^{14}$ Half of the respondents in a study by Duggal et al. had to pay from borrowed money or their life savings. ${ }^{15}$ The healthcare expense was further compounded by the ancillary expense like travel. This aspect has been reflected in previous studies emphasising the need of accessible healthcare. ${ }^{7,16}$

The survey found an understaffed primary care facility at these villages similar to the findings of previous such surveys held in different geographical rural locations in the country. The facilities were housed and equipped well, however the upkeep and availability of staff was a major concern. Provision of accommodation even though provided, is not utilised by the staff leading to delay in commutation to workplace. This compels the junior staff to take up more responsibilities and perform inefficiently due the sheer over burdening. The primary care centres were equipped to manage minor illnesses without any external support. The availability of locally trained paramedical personnel led to better penetration and implementation of maternal and child health services in these villages primarily due to their personal acquaintances. The non-availability of doctors at the state run facilities coupled by the distance, flourishes unorthodox practice of allopathic medicine by alternate medical practitioners due to their better availability and outreach. This situation is similar to various other rural areas of this country $\left({ }^{17-19}\right)$. The prescription patterns were unregulated. The system needs to acknowledge the important role being played by AWW/ASHA. They require motivation and adequate remuneration. The system should incorporate quaternary prevention to save the country from 'over-medicalization' and bring back the focus on interventions that are ethically acceptable. Medical Care Access and Preference were guided mostly by accessibility based and not need based. The respondents had over a period of time adjusted to the non-availability of state health infrastructure. The findings were similar to various other studies on this aspect $\left({ }^{4,7,20,21}\right)$. The avoidance of state run facilities were those which is reflected commonly among rural Indian population $\left(^{8,22,23}\right)$.

\section{Conclusion}

The rural healthcare setup in India is still in a primitive stage. However, there is considerable improvement in terms of participation of locally trained paramedical personnel. Such stakeholders have increased the penetration and acceptance of national health programmes. However, their role in the primary care has been is not adequately acknowledged. In order to boost the motivation level of these primary workers, adequate attention has to be given to their renumeration, education and recognition. The rural community stand aware about their health needs and prioritise healthcare as a major expense for overall development. There exists a huge void in terms of availability of professional healthcare at the rural level. This is primarily attributed to city side migration of skilled manpower and better personal prospects for the professional healthcare provider. The state has successfully implemented various health programmes until date. However, lot needs to be done in order to provide universal healthcare for all.

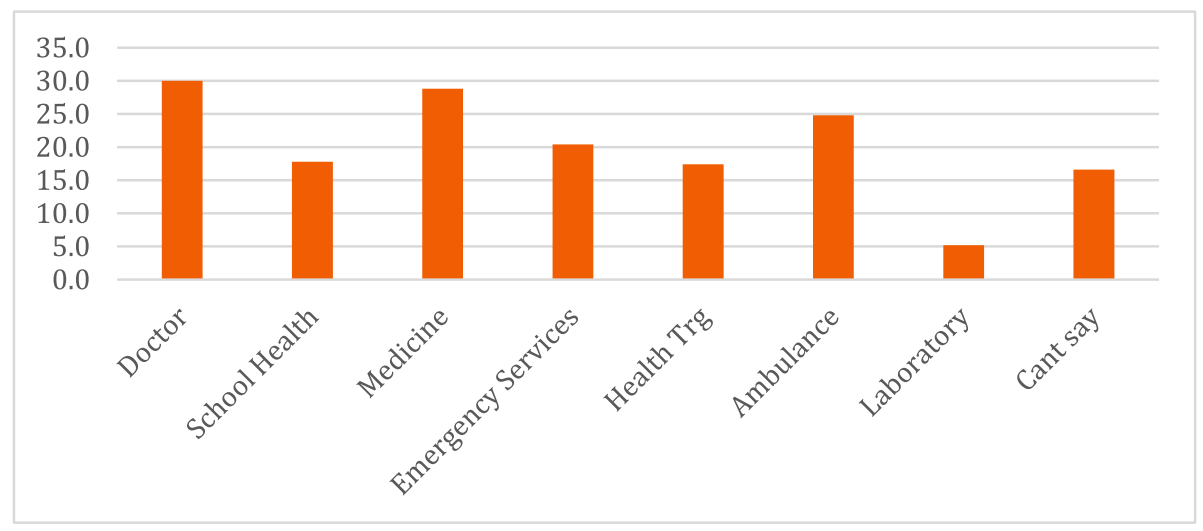

Fig. 8. Priority in Health expenditure. 


\section{Source(s) of support}

Self.

\section{Presentation at a meeting}

Nil.

\section{Conflicting interest}

Nil.

\section{References}

1. WHO. Report on the international conference on primary health care. Alma-Ata: USSR; 1978.

2. Pires-Alves FA, Cueto M. A década de Alma-Ata: a crise do desenvolvimento e a saúde internacional. [cited 2018 Jan 24]. Cien Saude Colet [Internet]. 2017 Jul;22(7):2135. 44. Available from: http://www.ncbi.nlm.nih.gov/pubmed/28723995.

3. Noor A, Gikandi P, Hay S, Muga R, Snow R. Creating spatially defined databases for equitable health service planning in low-income countries: the example of Kenya. [cited 2018 Jan 24]. Acta Trop [Internet]. 2004 Aug;91(3):239. 51. Available from: http://www.ncbi.nlm.nih.gov/pubmed/15246930.

4. Kumar V, Singh P. Access to healthcare among the Empowered Action Group (EAG) states of India: current status and impeding factors. [cited 2018 Jan 24]. Natl Med J India [Internet]. 2016;29(5):267. 73. Available from: http://www.ncbi.nlm.nih.gov/ pubmed/28098080.

5. Kumar R. Healthcare and medical education reforms in India: what lies ahead? [cited 2018 Jan 24]. J Fam Med Prim care [Internet]. 2013 Apr;2(2):123. 7. Available from: http://www.jfmpc.com/text.asp?2013/2/2/123/117394.

6. Office of the Registrar General Census Commissioner I, Census Bureau. Ministry of Home Affairs G of I. Census of India; 2011.

7. Kanuganti S, Sarkar AK, Singh AP, Arkatkar SS. Quantification of accessibility to health facilities in rural areas. [cited 2018 Jan 24]. Case Stud Transp Policy [Internet]. 2015 Sep 1;3(3):311. 20. Available from: https://www.sciencedirect.com/science/ article/pii/S2213624X14000480.

8. Singh T, Roy P, Jamir L, et al. Assessment of universal healthcare coverage in a district of north India: a rapid cross-sectional survey using tablet computers. In: Beck EJ, ed. PLoS One [Internet]. 2016 Jun 28; 2016 Jun 28. [cited 2018 Jan 24];vol. 11(6):e0157831. Available from:. http://www.ncbi.nlm.nih.gov/pubmed/ 27351743.

9. Purcell R, McGirr J. Preparing rural general practitioners and health services for climate change and extreme weather. [cited 2018 Jan 24]. Aust J Rural Health [Internet]. 2014 Feb;22(1):8-14. Available from: http://www.ncbi.nlm.nih.gov/ pubmed/24460994.

10. Walker R, Hassall J, Chaplin S, Congues J, Bajayo R, Mason W. Health promotion interventions to address climate change using a primary health care approach: a literature review. [cited 2018 Jan 24]. Health Promot J Austr [Internet]. 2011 Dec;22. Spec No:S6-12. Available from: http://www.ncbi.nlm.nih.gov/pubmed/22518912.

11. Singh JP. Distance patterns of rural to urban migration in India: a comparative overview of Kerala and West Bengal. [cited 2018 Jan 24]. Man India [Internet]. 1984 Jun;64(2):143-153. Available from: http://www.ncbi.nlm.nih.gov/pubmed/ 12313390.

12. Weinstein J. Urban growth in India: demographic and sociocultural prospects. [cited 2018 Jan 24]. Stud Comp Int Dev [Internet]. 1992;26(4):29-44. Available from: http://www.ncbi.nlm.nih.gov/pubmed/12286114.

13. The World Bank. Poverty \& Equity Data Portal [Internet]. 2011; 2011. [cited 2018 Jan 24]. Available from:. http://povertydata.worldbank.org/poverty/country/IND.

14. Mondal S, Kanjilal B, Peters DH, Lucas H. Catastrophic Out-of-pocket Payment for Health Care and its Impact on Households: Experience from West Bengal, India [cited 2018 Jan 24]; Available from:: http://www.chronicpoverty.org/uploads/ publication_files/mondal_et_al_health.pdf.

15. Duggal R. Financing Healthcare in India - Prospects for Health Insurance. [cited 2018 Jan 24]; Available from:: http://www.cehat.org/cehat/uploads/files/A 246 Financing healthcare.pdf.

16. Vidler M, Ramadurg U, Charantimath U, et al. Utilization of maternal health care services and their determinants in Karnataka State, India. [cited 2018 Jan 24]. Reprod Health [Internet]. 2016 Jun 8;13(S1):37. Available from: http://www.ncbi. nlm.nih.gov/pubmed/27356502.

17. Khan MU, Arief M, Ahmad A, et al. A cross-sectional survey on the attitudes and interests of rural population towards expanded pharmacist prescribing in India. [cited 2018 Jan 24]. Int JC Clin Pharm [Internet]. 2017 Apr 4;39(2):473. 7. Available from: http://www.ncbi.nlm.nih.gov/pubmed/28260131.

18. Barker AK, Brown K, Ahsan M, Sengupta S, Safdar N. What drives inappropriate antibiotic dispensing? A mixed-methods study of pharmacy employee perspectives in Haryana, India. [cited 2018 Jan 24]. BMJ Open [Internet]. 2017 Mar 2;7(3):e013190. Available from: http://www.ncbi.nlm.nih.gov/pubmed/28255093.

19. Das J, Chowdhury A, Hussam R, Banerjee AV. The impact of training informal health care providers in India: a randomized controlled trial. [cited 2018 Jan 24]. Science (80- ) [Internet]. 2016 Oct 7;354(6308):aaf7384. aaf7384. Available from: http:// www.sciencemag.org/cgi/doi/10.1126/science.aaf7384.

20. Jacobs B, Ir P, Bigdeli M, Annear PL, Van Damme W. Addressing access barriers to health services: an analytical framework for selecting appropriate interventions in low-income Asian countries. [cited 2018 Jan 24]. Health Policy Plan [Internet]. 2012 Jul 1;27(4):288-300. Available from: http://www.ncbi.nlm.nih.gov/pubmed/ 21565939.

21. Rebecchi A, Gola M, Kulkarni M, Lettieri E, Paoletti I, Capolongo S. Healthcare for all in emerging countries: a preliminary investigation of facilities in Kolkata, India. [cited 2018 Jan 24]. Ann Ist Super Sanita [Internet]. 2016;52(1):88-97. Available from: http://www.ncbi.nlm.nih.gov/pubmed/27033623.

22. Shankar D. Health sector reforms for 21st century healthcare. [cited 2018 Jan 24]. J Ayurveda Integr Med [Internet]. 2015;6(1):4. Available from: http://www.jaim.in/ text.asp?2015/6/1/4/154214.

23. Dodd W, King N, Humphries S, Little M, Dewey C. Self-reported morbidity and health service utilization in rural Tamil Nadu, India. [cited 2018 Jan 24]. Soc Sci Med [Internet]. 2016 Jul:161. 118-25. Available from: http://www.ncbi.nlm.nih.gov/ pubmed/27285663. 